\title{
THE VIBRODIAGNOSTICS OF DAMAGED GEARS OF PLANETARY GEARBOXES
}

This article deals with description of a diagnostic device used at the Department of Design and Machine Elements at the University of Zilina which has been built in order to measure, diagnose and evaluate gearbox faults by vibrodiagnostics. The article describes methods and damage creation process for tested gearboxes. Evaluation of different faults is also processed in this article as well as description of comparative measurements between real and artificially created pitting. Comparison of all measured data with SPM methods is also included.

Keywords: Vibrodiagnostics, frequency, spectrum, damage.

\section{Introduction}

The Vibrodiagnostics is considered to be one of most progressive maintenance methods. It offers possibilities to diagnose status and conditions of devices while they are fully operational [1]. The testing device has been constructed at the Department of Design and Machine Elements in order to measure and evaluate faults of components by analysing frequency spectra of gearboxes (Fig. 1). Laboratory research primarily aims at diagnostics of damaged gears of planetary gearboxes.

The testing device consists of one $15 \mathrm{~kW}$ electromotor controlled by a phase shifter, two planetary gearboxes type A2000 mounted in series and also one dynamometer. Components are coupled together by cardan shafts. The testing device is supplemented with noncontact sensors HBM T10F for RMP and torque measurement. Gearbox A 2000 is a planetary gearbox with two planetary gearings with involute spur gears [2].

The diagnostic apparatus was purchased from SKF and it contains six acceleration sensors with sensitivity of $100 \mathrm{mV} / \mathrm{g}$, on-line diagnostic unit type IMx-S and one PC equipped with @ ptitude analyst software. Both frequency analysis and envelope method for signal processing are used to determine gearbox faults.

Gearbox A2000 was tested for fault response at $1470 \pm 10$ RPM. Input shaft can rotate both clockwise and anticlockwise according to current needs.
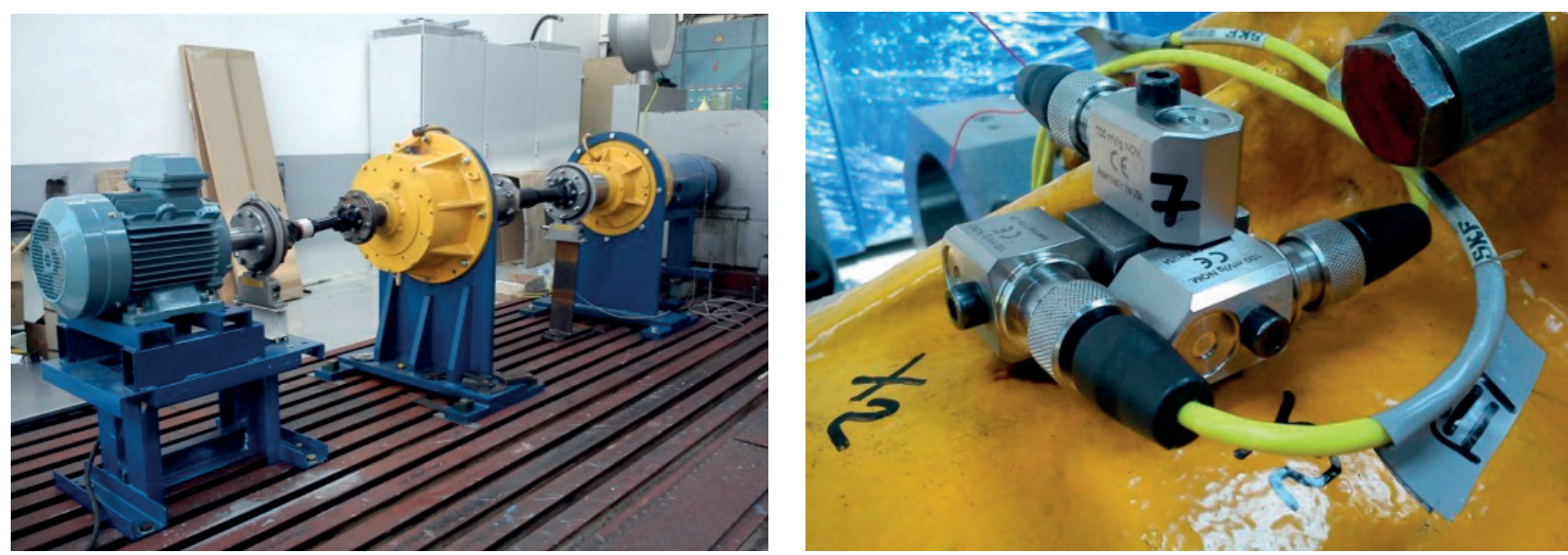

Fig. 1 The testing device used at the Department of Design and Machine Elements for diagnostics of planetary gearboxes' faults (left) and placement of vibration sensors (right)

\footnotetext{
* Lubos Kucera, Tomas Gajdosik, Jan Bucala

Department of Design and Machine Elements, Faculty of Mechanical Engineering, University of Zilina, Slovakia

E-mail: lubos.kucera@fstroj.uniza.sk
} 


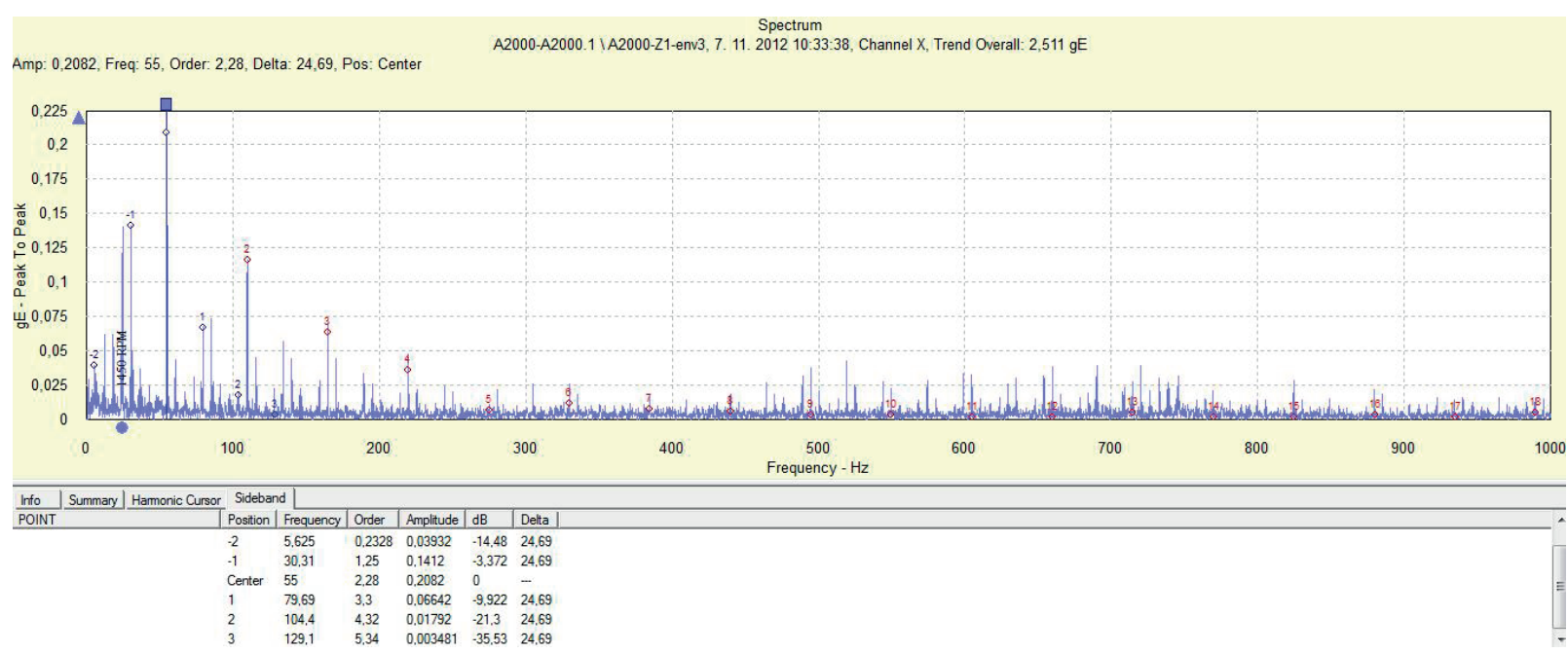

Fig. 2 The frequency spectrum of enveloped accelerations filter 3 for tooth of the sun gear damaged by the notch on its face area

Preliminary measurements of undamaged gearboxes needed to be done first in order to indicate key frequencies in spectrum of undamaged gearbox. Some components of gearboxes were artificially damaged later.

\section{Measurements of gears with teeth damaged by pitting}

The sun gear of the first planetary gearing was first to be damaged. First type of damage is represented by the notch on face area of one tooth. This damage was done with assumption of significant response within frequency spectrum. The damage can be seen in vibrations velocity spectrum by analysing sideband of gear mesh frequency of the first planetary gearing, because first amplitudes significantly surpassed magnitude of gear mesh frequency. Its effect was even more significant in enveloped accelerations spectrum filter 3 (Fig. 2). Frequency $55 \mathrm{~Hz}$ of damaged sun gear dominated throughout spectrum and its harmonic frequencies showed up (marked as red). Sideband was created around gear frequency with the delta equal to RPM frequency $24.69 \mathrm{~Hz}$ of damaged gear (marked as blue). Sideband can be clearly seen in vicinity of its harmonic frequency [3].

Small pitting was created on the opposite side of already damaged tooth after first fault simulated by the notch was evaluated. This type of fault showed similar effect when compared to tooth damaged by the notch in vibrations velocity spectrum, however amplitudes of sideband were not as significant. Fault effect in enveloped accelerations spectrum filter 3 also showed similar results as before and once again amplitude of the gear frequency of the damaged gear was significant, but values were lower when compared to those of tooth damaged by single notch [4] - [7]. Its harmonic frequencies were not as significant; however $2^{\text {nd }}, 3^{\text {rd }}$ and $4^{\text {th }}$ harmonic frequency is clearly visible.
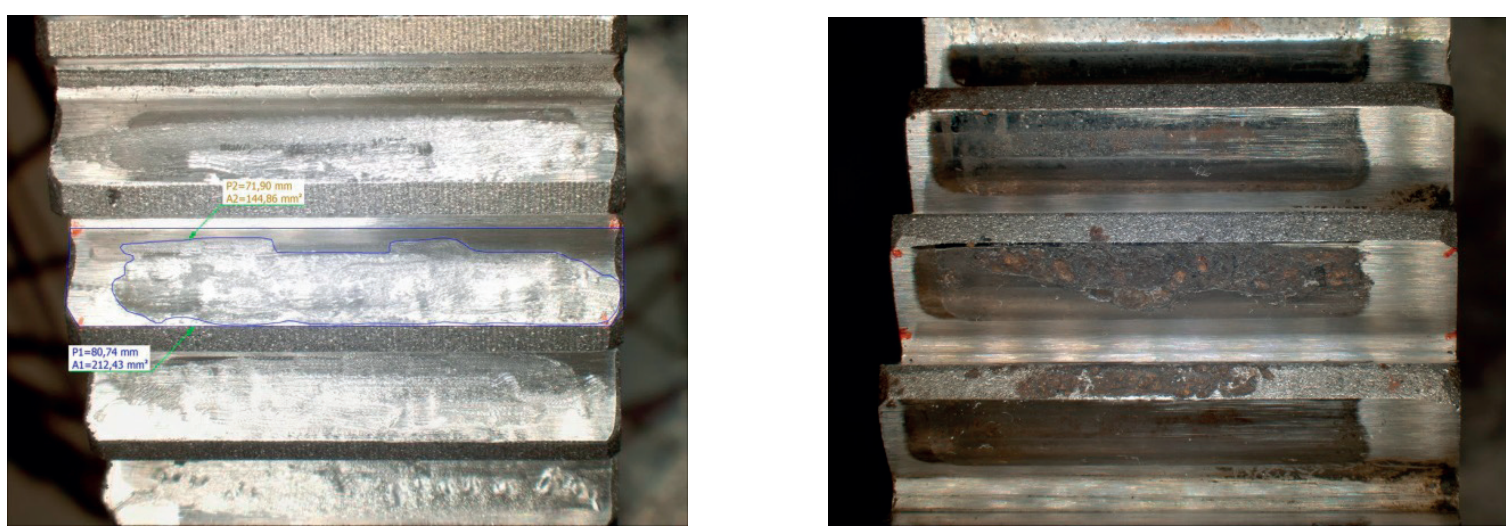

Fig. 3 Sun gear of planetary gearing damaged by artificially created pitting (left) and sun gear damaged by real pitting (right) 


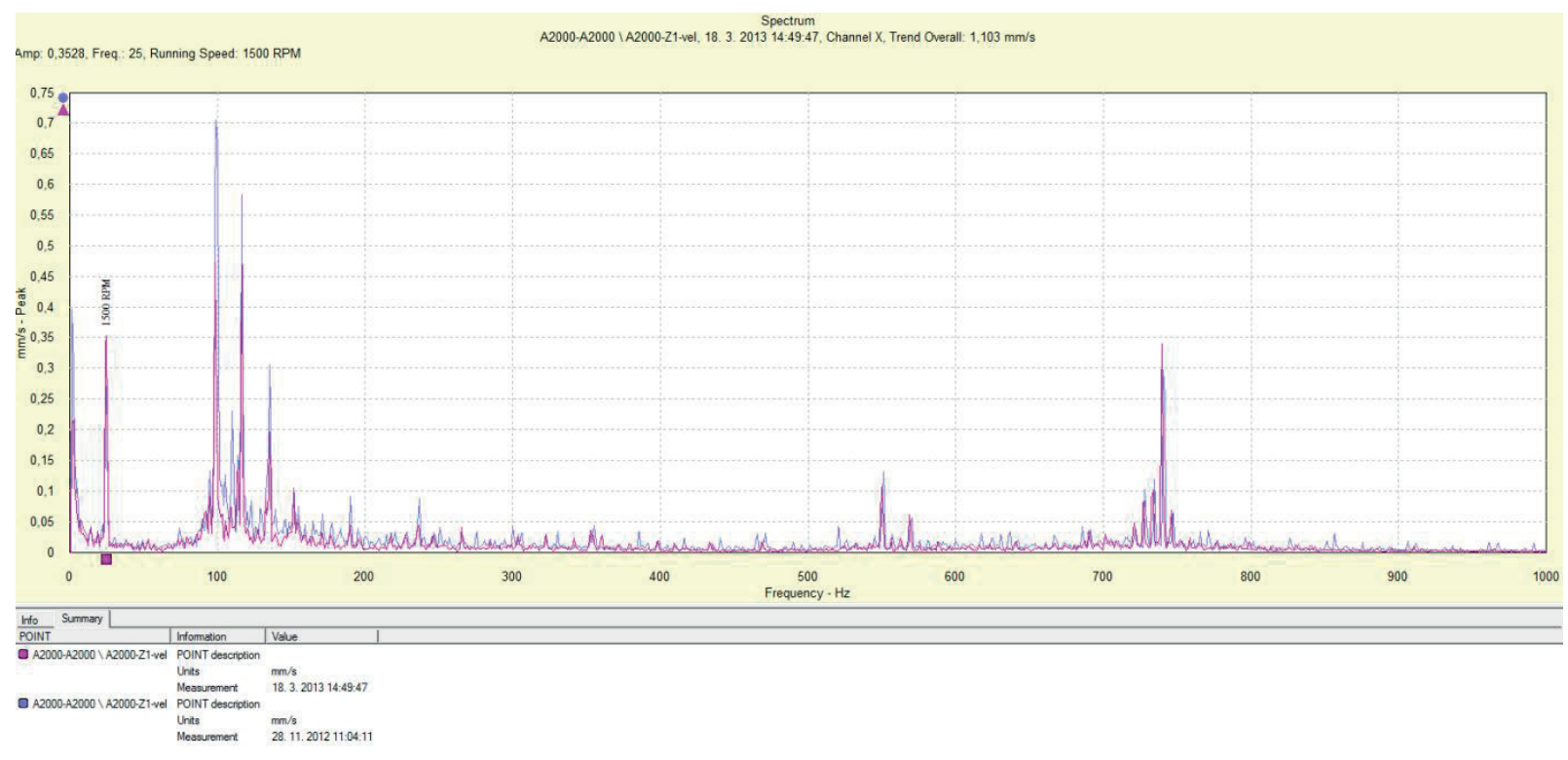

Fig. 4 The comparison of frequency spectra of gearbox with sun gear damaged by artificially created pitting on half of gear's teeth (blue) and sun gear damaged by real pitting (violet)

Pitting was created on every single tooth of the sun gear as experiments continued. Significant change occurred in vibrations velocity spectrum where one more sideband appeared with the delta equal to gear mesh frequency of damaged gear alongside regular gear mesh frequency of first planetary gearing. $2^{\text {nd }}$ and $3^{\text {rd }}$ harmonic frequency of gear mesh frequency also showed up (Fig. 4). Fault effect in enveloped accelerations spectrum filter 3 was similar to previous faults. Values of amplitude however increased greatly and amplitude of gear mesh frequency of the gear damaged by pitting on every tooth rose by $2100 \%$ when compared to the gear damaged by pitting only on one tooth.

In order to compare all measured data, another experiment with artificially created pitting on half of gear's teeth (on the same face area as damaged by the notch) took place (Fig. 3 left). Artificially damaged sun gear was replaced by another sun gear damaged by real pitting on half of gear's teeth (Fig. 3 right). After both spectra were measured and frequency spectra were compared, we came to the conclusion that artificially created pitting has very similar effect when compared to real pitting (Fig. 4). This comparison confirmed that measured data match reality and test method was suitable for this application as well [8] and [9].

Vibrations velocity frequency spectra with different pitting affected area of the sun gear of the first planetary gearing can be seen in Fig. 5. The upper part of spectra represents only one tooth damaged by pitting, middle part corresponds to all teeth damaged by pitting and lower part represents the gear damaged on half

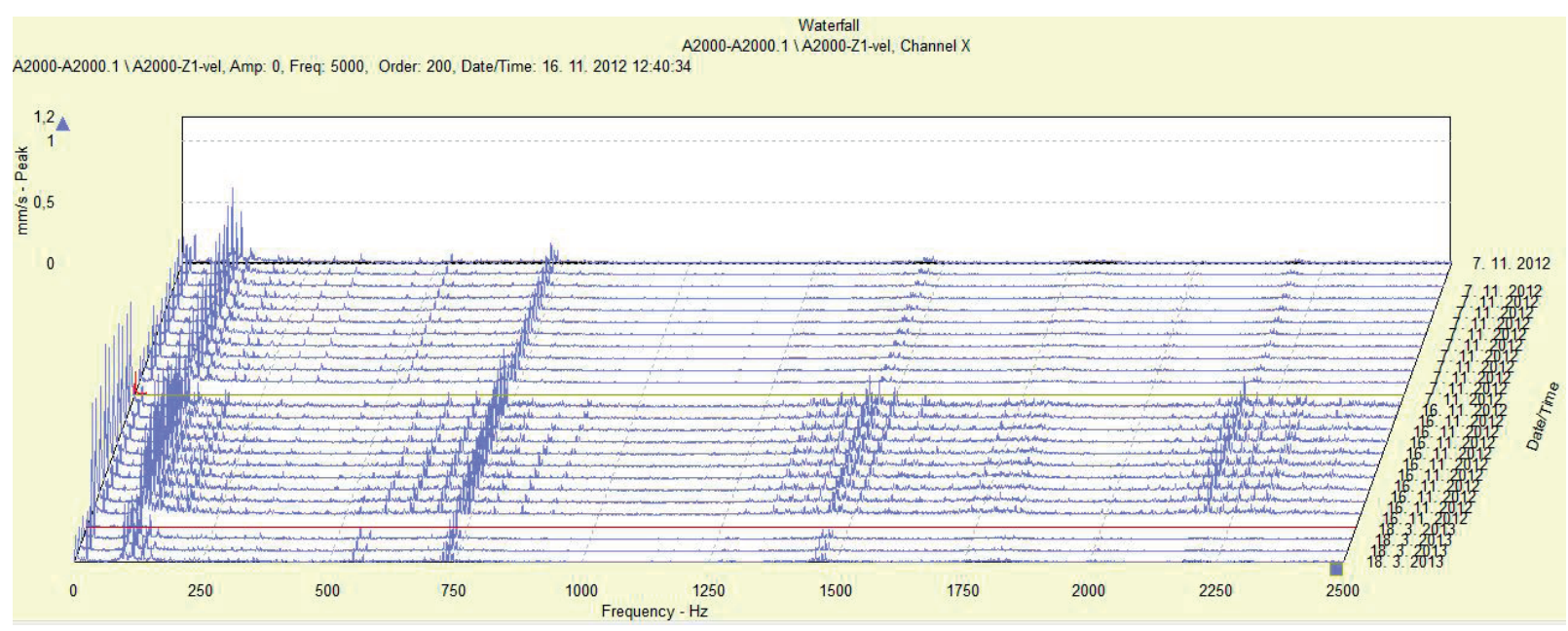

Fig. 5 Frequency spectrum of velocity of vibrations with differently damaged sun gears of first planetary gearing by pitting 
of its teeth by real pitting. Straight lines between measurements reflect time when the testing device was offline.

\section{Measurements of gears with teeth damaged by breaking}

Another phase involved sun gear with one tooth partially broken and later with whole missing tooth. Measurements were made on gears which were previously damaged by pitting on half of their teeth (Fig. 6).

There was no significant change in vibrations velocity spectrum (Fig. 7) compared to the sun gear damaged by pitting on half of its teeth [10]. Enveloped accelerations spectrum filter 3 - from $5 \mathrm{~Hz}$ to $1 \mathrm{kHz}$ (Fig. 8) also had similar characteristic compared to same sun gear with no missing teeth, but amplitude of gear mesh frequency and its harmonic frequencies had higher values compared to pitting damaged sun gear.

\section{Comparative measurements of two different methods}

Comparative measurements were made in cooperation with vibrodiagnostic specialists from SPM Instrument s.r.o. SPM HD and SPM Spectrum methods were used to examine current status of the gearbox. The gearbox was damaged by missing tooth and pitting on the sun gear and notch type damage was made on the satellite gear.

Frequency spectrum measured by SPM HD method is shown in Fig. 9. Teeth frequency of damaged gear $(54.976 \mathrm{~Hz})$ and its harmonic frequencies within spectrum are marked by numbers. Figure 10 contains data measured by enveloped accelerations method filter 3 where teeth frequency $(55 \mathrm{~Hz}$ ) and its harmonic frequencies of damaged gear are also marked by numbers. Spectra
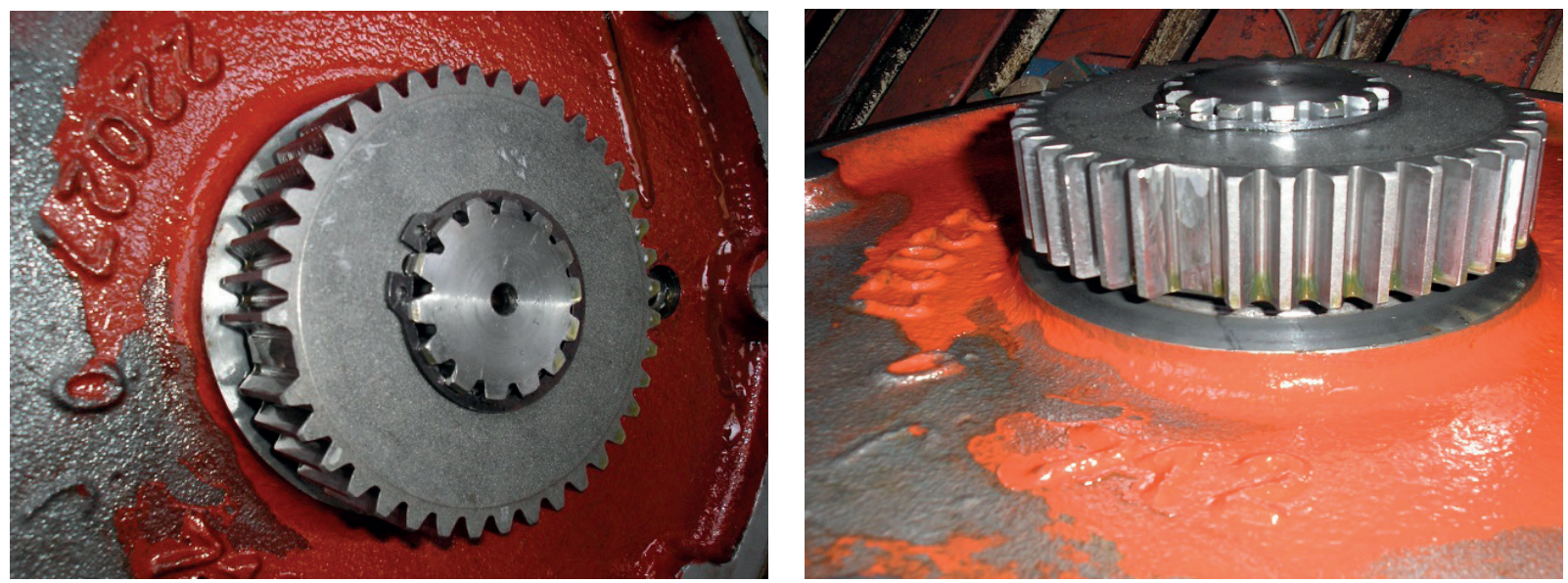

Fig. 6 Sun gear with one missing tooth

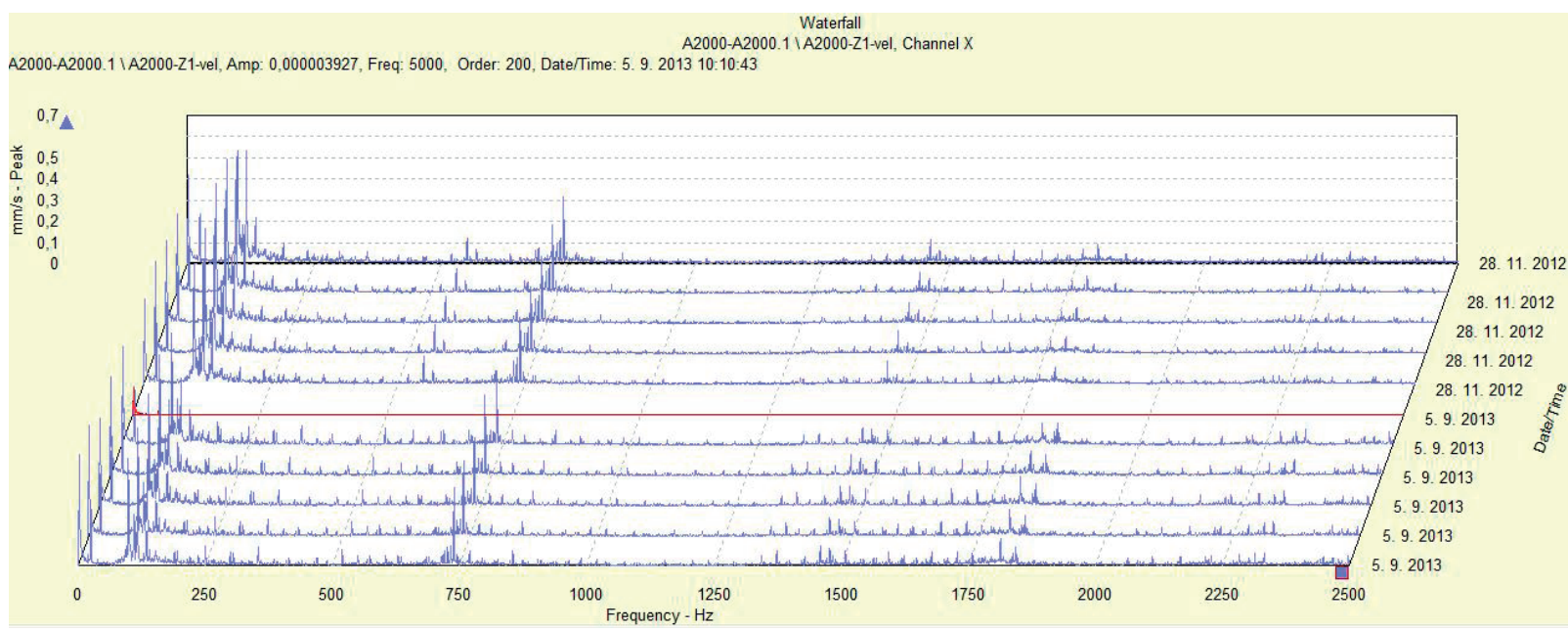

Fig. 7 The comparison of frequency spectra of vibrations for pitting created on half of teeth of sun gear (upper part) and for gear damaged by same pitting with one missing tooth (lower part) 


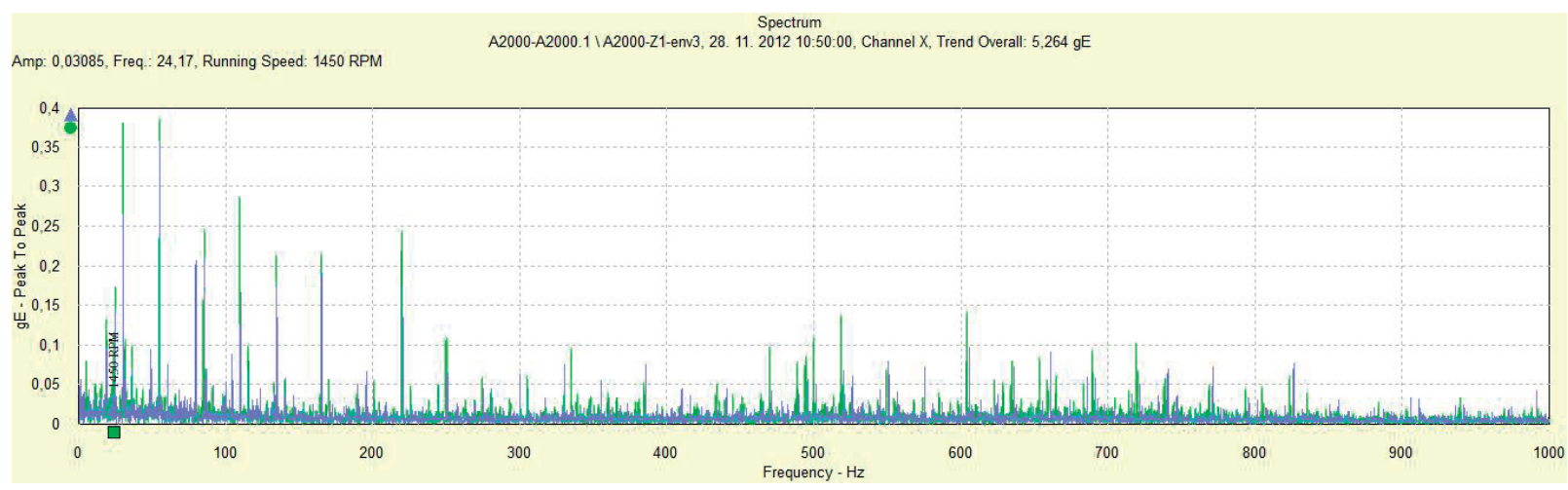

Fig. 8 The comparison of frequency spectra of enveloped acceleration filter 3 for pitting created on half of teeth of sun gear (blue) and for gear damaged by same pitting with one missing tooth (green)

in both figures are very similar with small difference of amplitude magnitude for $6^{\text {th }}, 7^{\text {th }}$ and $8^{\text {th }}$ harmonic frequency because these harmonic frequencies have much lower amplitudes with enveloped accelerations method.

Vibrations velocity frequency spectrum obtained by SPM Spectrum method can be seen in Fig. 11. Spectrum's shape is very similar to SKF methods in direct comparison (Fig. 12), difference is in amplitude magnitudes. Spectra in both figures highlighted amplitudes of sideband with the spacing of teeth frequency of damaged sun gear $(55 \mathrm{~Hz})$ and amplitude of sideband of gear mesh frequency of the first planetary gearing which has high value of amplitude dominating through whole spectrum.

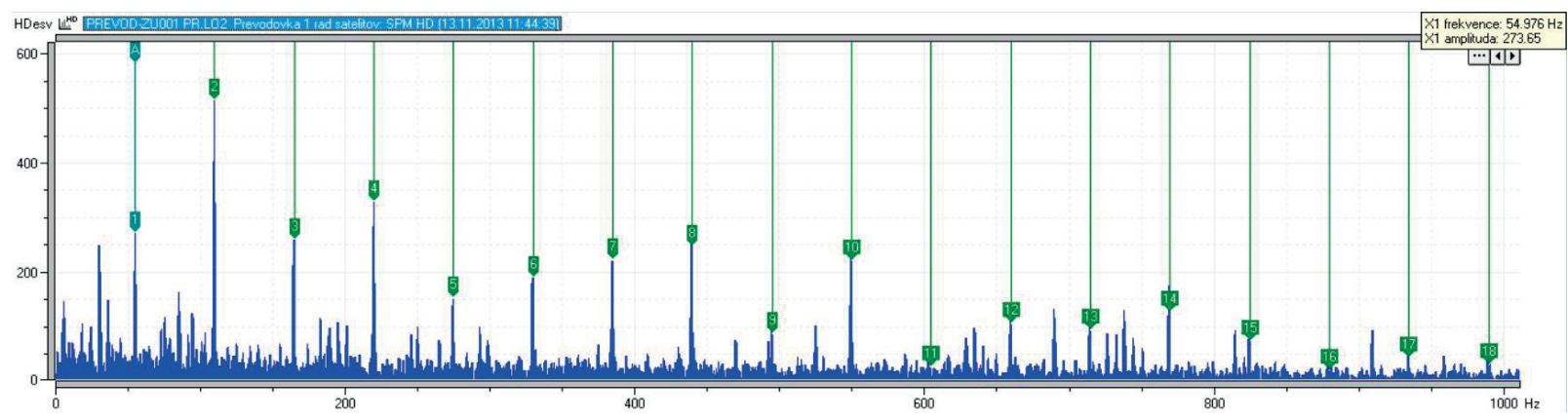

Fig. 9 Frequency spectrum measured by SPM HD method

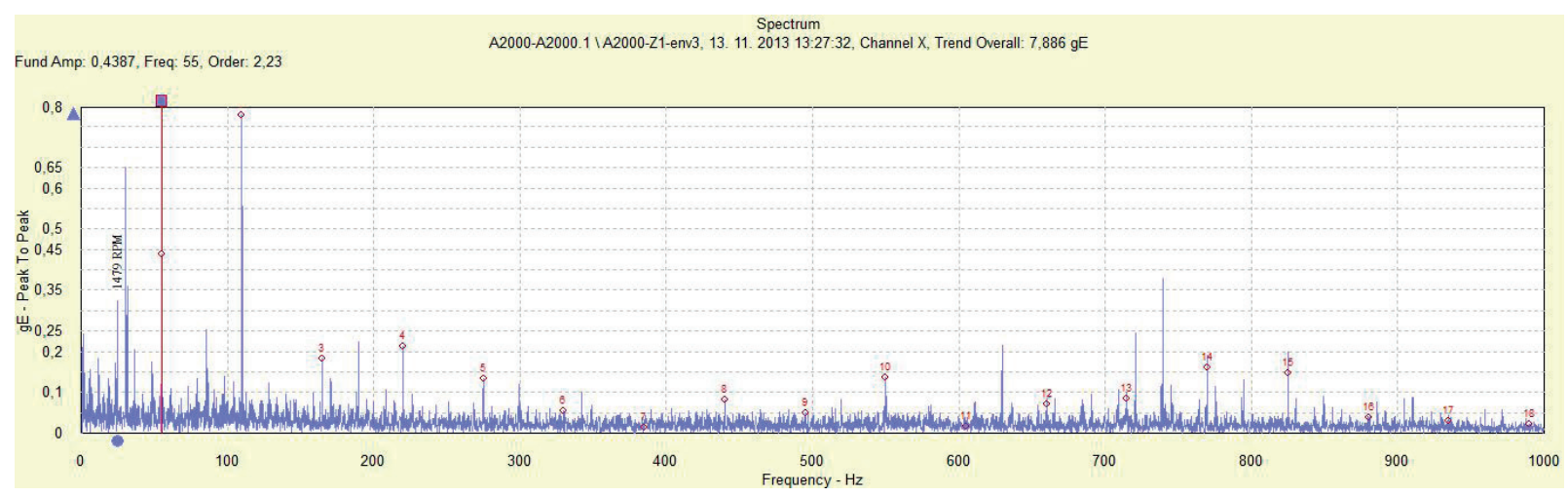

Fig. 10 Frequency spectrum measured by enveloped accelerations method (SKF) 


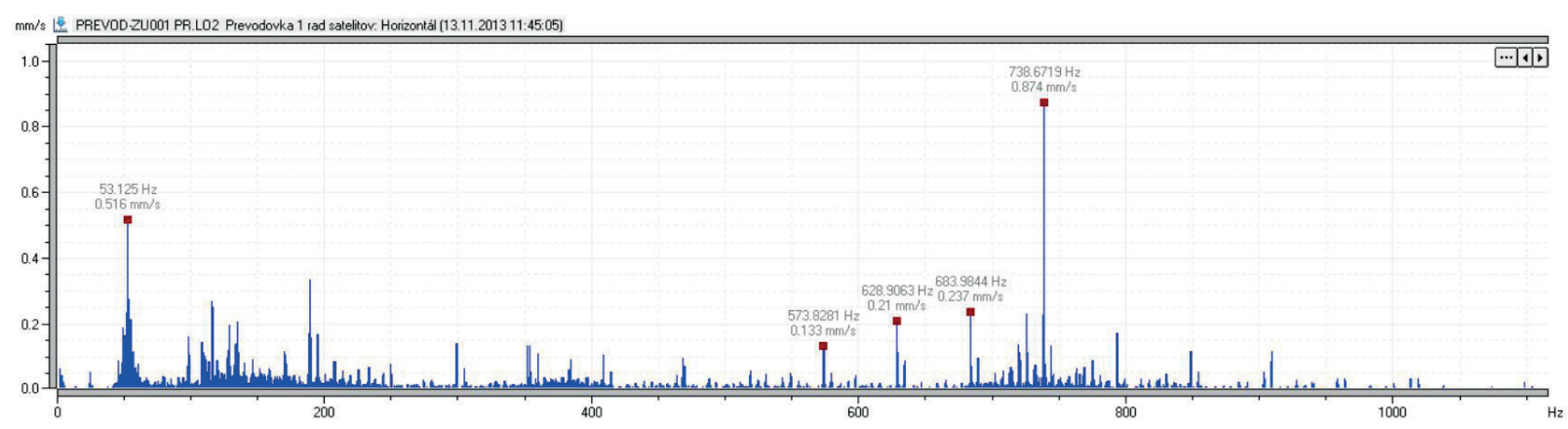

Fig. 11 Frequency spectrum of vibrations velocity measured by SPM Spectrum method

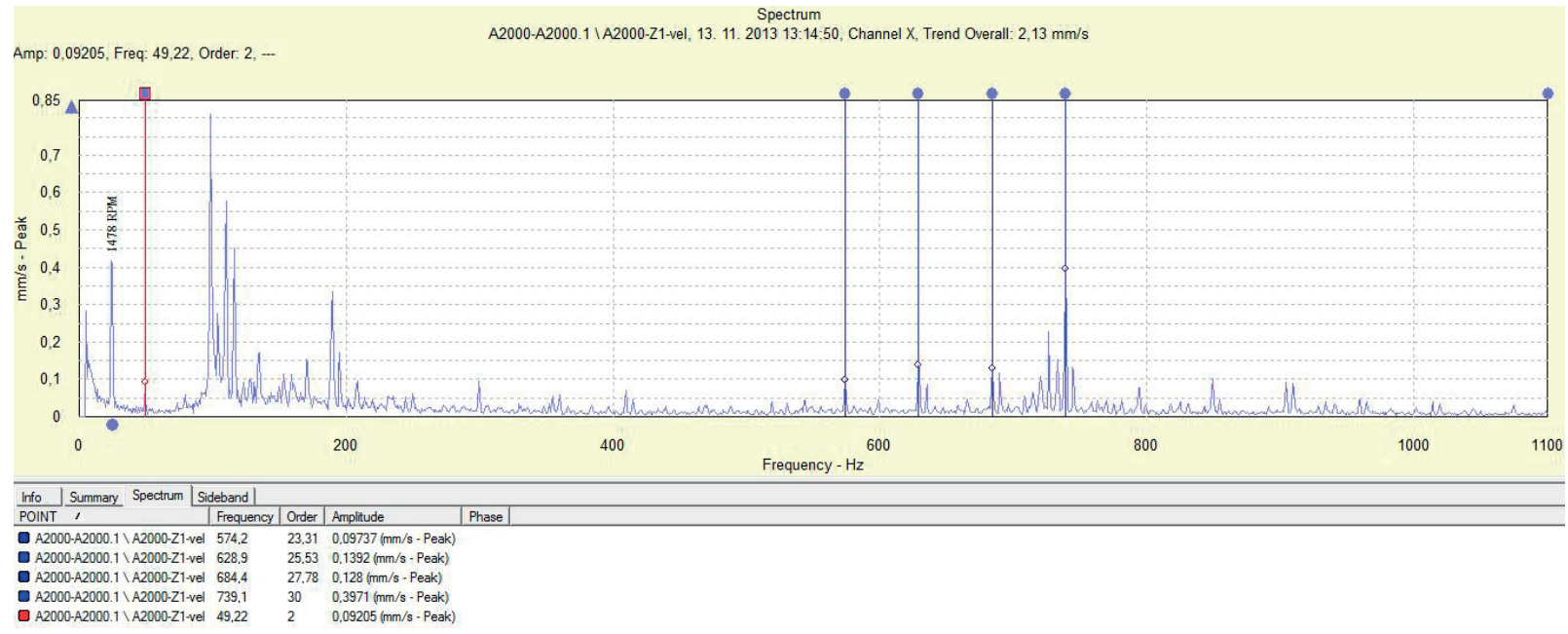

Fig. 12 Frequency spectrum of vibrations velocity measured by SKF diagnostic methods

It is necessary to mention that influence of damaged planet gear has not been detected either in vibrations velocity spectrum or in enveloped accelerations spectrum [11], [12] and [13].

\section{Conclusion}

Measurements we made so far clearly show artificially developed faults of the sun gear in high frequency vibrations velocity spectrum and enveloped accelerations spectrum for given gearbox correspond to vibration responses of faults developed under real conditions for same gearbox and, therefore, confirm used methods of measurements. Similarity of SKF and SPM methods was proved by comparing both results. Effects of faults are also similar although technology for signal processing differs significantly between these two methods.

This article was created with support of Slovak Research and Development Agency (SRDA) based on agreement No. SUSPP-001409 and under project No. APVV 087-10: "Intelligent diagnostic systems of gearboxes and their components".

\section{References}

[1] PRODAJ, J.: Applications and Diagnosis of Selected Nodes of Stationary and Mobile Gear System (in Slovak), Dissertation thesis, Zilina, 2012.

[2] GAJDOSIK, T., BUCALA, J., KOVALICEK, M.: Vibrodiagnostic of Gearboxes, Proc. of intern. conference Transcom 2013, Zilina, 2013.

[3] KUCERA, L., GAJDOSIK, T.: The Vibrodiagnostic of Gears, 54 $4^{\text {th }}$ Intern. conference of machine design departments, September 2013, Hejnice: Liberec: Technical university, 93-98, 2013. ISBN 978-80-7372-986-8. 
[4] SAPIETA, M., STEVKA, O., DEKYS, V.: Localization Luders Band in Infrared Spectrum, Applied Mechanics and Materials, vol. 420, 2013, 194-201, ISSN 1660-9336.

[5] DEKYS, V., DVOULETY, O.: A Contribution to the Condition Monitoring of Fans, Zeszyty naukowe Politechniki Slaskiej: Transport, z. 76, No. 1865, 2012, 49-56. ISSN 0209-3324.

[6] DEKYS, V., SAGA, M., ZMINDAK, M.: Damage Detection Based on Dynamic Measurements, New methods of damage and failure analysis of structural parts, September, 2012, Ostrava: Technicka univerzita, 41-49, ISBN 978-80-248-2802-2.

[7] VASKO, M., SAGA, M., DEKYS, V.: Contribution to Numerical Analysis of Uncertain Mechanical Systems Using Probability and Possibility Theory, Advances in mechanisms design, Proc. of TMM 2012, Dordrecht: Springer Science+Business Media, ISBN 97894-007-5124-8, (Mechanisms and machine science, vol. 8, 263-269. ISSN 2211-0984).

[8] KOPAS, P., SAGA, M., UHRICIK, M.: Contribution to Multiaxial Damage Calculation Using FEM, Applied Mechanics and Materials, vol. 420, 2013, 318-324. ISSN 1660-9336.

[9] NEMECEK, M., DEJL, Z.: Geometric Calculations of the Chamfered Tip and the Protuberance Undercut of a Tooth Profile (Conference Paper), ASME 2011 Intern. Design Engineering Technical Conferences on Computers and Information in Engineering Conference, IDETC/CIE 2011, Washington: DC, August 2011; Code 91020.

[10] NEMECEK, M.: Problems with the Design of Internal Gearing with Extreme Parameters (Conference Paper), 2007, Proc. of the ASME International Design Engineering Technical Conferences and Computers and Information in Engineering Conference, DETC2007, vol. 7, 2008, 199-206,

$10^{\text {th }}$ Intern. Power Transmission and Gearing Conference, presented at 2007 ASME International Design Engineering Technical Conferences and Computers and Information in Engineering Conference, IDETC/CIE2007; Las Vegas, NV, September 2007, Code 72172.

[11] KOHAR, R., HRCEK, S.: Dynamic Analysis of Rolling Bearings with Elastic Cage, Proc. of 54 ${ }^{\text {th }}$ intern. Conference of Machine Design Departments, 211-216, September 2013, Hejnice: Liberec: Technical university, 2013. ISBN 978-80-7372-986-8.

[12] KOHAR, R., HRCEK, S., MEDVECKY, S.: Usage of Dynamic Analysis to Determine Force Interactions between Components of Rolling Bearings, Communications - Scientific Letters of the University of Zilina, vol. 14, No. 3, 2012, 62-67. ISSN 1335-4205.

[13] HRCEK, S., KOHAR, R., MEDVECKY, S.: Determination of the Maximum Roller bearing Load with Regards to Durability thereof using FEM Analysis, Communications - Scientific Letters of the University of Zilina, vol. 14, No. 3, 2012, 55-61. ISSN 13354205. 